\title{
Effects of non-magnetic phase and deposition temperature on magnetic properties of FePt-MgO granular thin films on single-crystal MgO substrate
}

\author{
Z.G. Qiu ${ }^{1,2}$,D.C. Zeng ${ }^{1,2^{*}}$,L.Z. Zhao ${ }^{1}$, J. Wang ${ }^{1}$, H.Y. Yu ${ }^{1,2}$,Z.W. Liu ${ }^{1}$, J.P. Liu ${ }^{3 *}$, K.S. Zhou ${ }^{1}$ \\ 1. School of Materials Science and Engineering, South China University of Technology, Guangzhou \\ 510640, China
}

2. Zhongshan R\&D Center for Materials Surface and Thin Films Technology of the South China University of Technology, Gent Materials Surface Technology (Guangdong) Co., Ltd, Zhongshan 528437, China

3. Department of Physics, University of Texas at Arlington, Arlington 76019, United States

\begin{abstract}
$(\mathrm{FePt})_{100-x}(\mathrm{MgO})_{x}$ granular thin films were fabricated by using co-sputtering on single crystal $\mathrm{MgO}$ substrate at different deposition temperatures followed by a high-temperature annealing. The adding $\mathrm{MgO}$ was found to have the following effects: 1) high fraction of $\mathrm{MgO}$ phase (70 vol.\%) degraded the $\mathrm{L} 1_{0}$ phase transformation; 2) FePt grains embedded in $\mathrm{MgO}$ matrix were well separated, leading to minimized exchange interaction between the FePt grains; 3) 55 vol.\% fraction of $\mathrm{MgO}$ was optimal for the $\mathrm{L} 1_{0}$-FePt phase formation with highest coercivity, due to the formation of granular structure, which was also verified by comparing the structure and properties of $\mathrm{FePt} / \mathrm{MgO}$ bilayer films. Deposition temperature has also effect on the magnetic properties of FePt-MgO films. Room temperature deposition did not result in the $\mathrm{L} 1_{0}$ phase even after annealing at $800^{\circ} \mathrm{C}$. However, the magnetic properties of the films deposited at $200^{\circ} \mathrm{C}$ were better than those deposited at $300^{\circ} \mathrm{C}$. The low coercivity resulted from elevated deposition temperature was attributed to the thermal expansion and competitively growth among $\mathrm{FePt}$ and $\mathrm{MgO}$ grains. The results revealed that adding appropriate amount of $\mathrm{MgO}(55 \mathrm{vol} . \%)$ can be achieved by finding a proper deposition temperature $\left(200^{\circ} \mathrm{C}\right)$, well-defined granular $\mathrm{L} 1_{0}-\mathrm{FePt}$ films with fine grain distribution, high coercivity and small domain size.
\end{abstract}

Key words:

$\mathrm{L} 1_{0}$-FePt granular film; $\mathrm{MgO}$ matrix; Deposition temperature; Exchange coupling effect

\footnotetext{
* Corresponding author

E-mail addresses: medczeng@ @scut.edu.cn, tel: +86 20-87111278(D.C. Zeng);

pliu@uta.edu, tel: +1 817-2722815 (J. P. Liu)
} 


\section{Introduction}

$\mathrm{L1}_{0}$-FePt film has the high magnetocystalline anisotropy energy $\left(K_{u}\right)$ and high coercivity $\left(H_{C}\right)$, so that it is an ideal high density magnetic recording material ${ }^{[1]}$. However, $\mathrm{L} 1_{0}$-FePt ordered phase is obtained by high temperature annealing or deposition, which is prone to increase the grain size of FePt. The large size grains cause the increase of surface roughness and exchange coupling effects. It is detrimental to the high density recording. Eventually, it is crucial to form the granular or isolated FePt films by adding the non-magnetic matrix, which can decouple the hard phase grains and improve the reliable recording signals. It was reported that some researchers attempted to obtain the granular microstructure by using various non-magnetic materials ${ }^{[2-4]} . \mathrm{MgO}$ is chosen for its widely application in the tunnel junction devices and has a suitable lattice mismatch with FePt $(4 \%)^{[5-7]} . \mathrm{In}$ general, FePt-MgO nano-granular film can be formed by either FePt/MgO multilayer deposition or co-sputtering of FePt and $\mathrm{MgO}$ after the annealing ${ }^{[8-9]}$. Nevertheless, excessive amount of $\mathrm{MgO}$ non-magnetic phase will degrade the transformation of $\mathrm{L}_{0}-\mathrm{FePt}^{[10]}$. It may be caused by the change of exchange coupling length due to the isolation by $\mathrm{MgO}$ matrix. For that reason, it is necessary to control the appropriate concentrations of doping non-magnetic phase.

As the results, the FePt grains embedded in the $\mathrm{MgO}$ matrix was studied to minimize the grain size of the FePt grains and segregate the magnetic phase ${ }^{[11]}$. It is significant to enhance the signal-to-noise ratio (SNR) of the film for recording ${ }^{[12]}$. Z. Dong, et al ${ }^{[13]}$ showed the magnetization behavior was also affected by different grain size distribution by using 3D micromagentic studies. However, the mechanisms of thedoping amount of $\mathrm{MgO}$ in $\mathrm{FePt}$ films are still rarely investigated.The optimal amount of $\mathrm{MgO}$ non-magnetic phase can effectively decrease not only the exchange coupled effects between the hard magnetic $\mathrm{L}_{0}$ - $\mathrm{FePt}$ grains, but also the grain size after high temperature annealing.

In this paper, the utilization of single crystal $\mathrm{MgO}$ substrate can induce the growth of the $\mathrm{MgO}$ grains because of the homogeneous structure. The well-isolated FePt grains separated by the $\mathrm{MgO}$ matrix, the magnetically decoupled hard phase grains, large magnetic anisotropy constant and high coercivity were obtained ${ }^{[14-15]}$. It provides a novel feasible method to fabricate the granular structureFePt films for high density magnetic recording media with low exchange coupling and high thermal stability. 


\section{Experimental}

The FePt-MgO granular thin films and FePt/MgO bilayer thin films were fabricated by dc magnetron sputtering system at various temperatures (room temperature, $200^{\circ} \mathrm{C}$ and $300^{\circ} \mathrm{C}$ ). $(\mathrm{FePt})_{100-\mathrm{x}}(\mathrm{MgO})_{\mathrm{x}}$ films were prepared by co-sputtering. A Pt target was symmetrically distributed with fan shaped Fe chips. The purity of the Fe, $\mathrm{Pt}$ and $\mathrm{MgO}$ were higher than 99.99\%. The substrate was $\mathrm{MgO}<100>$ single crystal material. The base pressure of the sputter chamber was higher than $7.0 \times 10^{-5} \mathrm{~Pa}$ and the argon pressure was fixed at $0.7 \mathrm{~Pa}$. The chemical composition of FePt phase was $\mathrm{Fe}_{55} \mathrm{Pt}_{45}$, which was determined by Energy dispersive spectrometry (EDS, NOVA NANOSEM 430). The as-deposited film was annealed in vacuum at $800^{\circ} \mathrm{C}$ for 1 hour. The total thicknesses of the FePt $-\mathrm{MgO}$ film were fixed at $60 \mathrm{~nm}$. The FePt layer was $27 \mathrm{~nm}$ and $\mathrm{MgO}$ layer was $33 \mathrm{~nm}$ in the $\mathrm{FePt} / \mathrm{MgO}$ bilayer film. The total thickness of bilayer thin film was consistent with the $[\mathrm{FePt}]_{45}[\mathrm{MgO}]_{55}$ filmby varying the deposition rate and time of $\mathrm{FePt}$ and $\mathrm{MgO}$. The RF sputtering powers of $\mathrm{MgO}$ were used to control the volume fraction of $\mathrm{MgO}$ in the FePt-MgO film. Since, the $\mathrm{MgO}$ content of the film was obtained by using the formula ${ }^{[16]}:\left[\mathrm{R}_{\mathrm{MgO}} /\left(\mathrm{R}_{\mathrm{FePt}}+\mathrm{R}_{\mathrm{MgO}}\right)\right] \times 100 \mathrm{vol} . \%$, where $\mathrm{R}$ was the sputtering rate. The structure, magnetic properties and domains of the FePt films were characterized by X-ray diffraction (XRD, Philips X'Pert Pro, $\mathrm{Cu}-\mathrm{K}$ ), atomic/magnetic force microscope (AFM/MFM, Asylum Cypher), and vibrating sample magnetometer (VSM setup: PPMS-9 Quantum Design Co.) with a maximum applied field of 9T. The plane-view morphology and selected area electron diffractions (SAEDs) were measured by Transmission electron microscopy (TEM, JEOL JEM2100F).

\section{Result and discussion}

\subsection{Phase and microstructure}

Fig. 1 showed the XRD patterns for different composition $\mathrm{FePt}-\mathrm{MgO}$ films annealed at $800^{\circ} \mathrm{C}$. It was recognized that the $\mathrm{L} 1_{0}$ phase formation was prohibited by the deposition of FePt-MgO films at room temperature, because the superlattice diffraction peak (001) and fundamental peak (002) of $\mathrm{L}_{0}$ phase were not observed at the room temperature deposited films.

The $\mathrm{L} 1_{0}-\mathrm{FePt}$ phase transformation can be enhanced with increasing the deposition temperature from room temperature to $200^{\circ} \mathrm{C}$. The films with small fraction of $\mathrm{FePt}(30 \%)$ were difficult to form L1 $1_{0}$-phase even after high temperature annealing, as shown in Fig. 1a.When the deposition 
temperature was as high as $300^{\circ} \mathrm{C}$, the $\mathrm{FePt}$ was almost decomposed into $\mathrm{Fe}_{3} \mathrm{O}_{4}$ and $\mathrm{PtO}$ for the higher diffusivity of $\mathrm{O}$ atoms at high temperature deposition. Also adding higher fraction of $\mathrm{MgO}$ (vol. $70 \%$ ) was prone to generate the oxidation phase $\left(\mathrm{Fe}_{3} \mathrm{O}_{4}\right.$ and $\left.\mathrm{PtO}\right)$. Based on the theory of thermodynamics, the excessive density of oxygen element and sufficient thermal energy in the system provided the possibility to form the $\mathrm{FeO}_{\mathrm{x}}$, which was certified by the previous studies on FePt-ZnO films ${ }^{[17]}$. The existence of fcc-FePt (200) peak was found in the annealed films and the PtO phase was disappeared for the increasing fraction of FePt, shown in Fig. 1b and Fig. 1c. Additionally, the strong $\mathrm{L} 1_{0}$-FePt superlattice diffraction peak (001) was appeared when the composition of the films was $(\mathrm{FePt})_{45}(\mathrm{MgO})_{55}$ and $(\mathrm{FePt})_{60}(\mathrm{MgO})_{40}$.

However, even if for the films with larger fraction of FePt, the oxidation phase can also be formed by increasing the deposition temperature. It is logical to evaluate the $\mathrm{L} 1_{0}$-FePt transformation degree by calculating the ordering parameter, which is obtained by ${ }^{[18]}$ :

$$
S \cong 0.85\left[\frac{I_{001}}{I_{002}}\right]^{1 / 2}
$$

where $I(001)$ and $I(002)$ represent the integrated intensities of the (001) and (002) diffraction peaks from the XRD patterns (Fig. 1).

Fig. 1d showed the ordering parameter as the function of FePt deposition temperature. It was apparent to find that the ordering parameter was not able to calculate at the room temperature deposition due to the disappearance of $\mathrm{L} 1_{0}-\mathrm{FePt}(001)$ peak. When the deposition temperature was $200^{\circ} \mathrm{C}, \mathrm{L} 1_{0}$-FePt ordering parameter was much higher than the films deposited at $300^{\circ} \mathrm{C}$. It implied that the $\mathrm{L} 1_{0}-\mathrm{FePt}$ phase was beneficial to form at $200^{\circ} \mathrm{C}$ deposition. Fig. $2 \mathrm{a}$ showed the shift of $\mathrm{FePt}$ (111) peak from $2 \theta=40.1^{\circ}$ to $41.6^{\circ}$ as the deposition temperature elevating to $200^{\circ} \mathrm{C}$. The inset indicated the $\mathrm{L} 1_{0}-\mathrm{FePt}(001)$ peak of the film deposited at $200^{\circ} \mathrm{C}$ had $2 \theta$ angle of $24^{\circ}$, which was slightly higher than that $\left(23.5^{\circ}\right)$ of the film deposited at $300^{\circ} \mathrm{C}$. It indicated the $\mathrm{L} 1_{0}$ phase ordering was enhanced at $200^{\circ} \mathrm{C}$ deposition. For the $(\mathrm{FePt})_{60}(\mathrm{MgO})_{40}$ films, the $\mathrm{L} 1_{0}-\mathrm{FePt}(111)$ peak of the film deposited at $200^{\circ} \mathrm{C}$ also had higher $2 \theta$ angle than the film deposited at $300^{\circ} \mathrm{C}$, shown in Fig. $2 \mathrm{~b}$. However, the FWHM of the $\mathrm{L}_{0}$-FePt (001) and (111) peaks was decreased, which indicated the increase of $\mathrm{L} 1_{0}$-FePt grain size with increasing FePt fraction.

The grain size was calculated by scherrer equation from XRD patterns and the results were shown in Fig. 2c. It demonstrated that the size of FePt grains became larger as the deposition 
temperature increased. The grain size of $200^{\circ} \mathrm{C}$ or $300^{\circ} \mathrm{C}$ deposited films were about $23-26 \mathrm{~nm}$ after $800^{\circ} \mathrm{C}$ annealing. Fig. 3 showed the plane-view morphologies of $(\mathrm{FePt})_{45}(\mathrm{MgO})_{55}$ films. In Fig. 3a, the average grain size was $25 \mathrm{~nm}$ and the major phases were $\mathrm{L} 1_{0}-\mathrm{FePt}$ and $\mathrm{MgO}$ shown in the inset SAED, whereas, the granular structure can not be obviously seen in plane-view TEM dark field image. For the $300^{\circ} \mathrm{C}$ deposited film, shown in Fig. 3b, the FePt grain size was also about $24 \mathrm{~nm}$ and the phase was not changed, which was consistent with the calculation results. The grain size of the different temperature deposited films was only slightly changed and the growth of FePt grains was effectively limited by $\mathrm{MgO}$ matrix. Additionally, the grain size of $(\mathrm{FePt})_{60}(\mathrm{MgO})_{40}$ film was larger than the other films, which was related to the not well-separated structure and the agglomeration of the FePt grains.

The decrease of ordering parameter for the FePt-MgO films at $300^{\circ} \mathrm{C}$ deposition was caused by the different thermal expansion coefficients of FePt and $\mathrm{MgO}$. According to the previous research, both the thermal expansion coefficient and melting point of the materials reflects the atomic bonding and interaction force ${ }^{[19]}$. It concludes that if the the melting point of the material is high, it will reduce thermal expansion coefficient. The bonding force is stronger between $\mathrm{Mg}$ and $\mathrm{O}$ atoms because of higher melting point $\left(2800^{\circ} \mathrm{C}\right)$ compared with $\mathrm{FePt}\left(\right.$ about $\left.1300^{\circ} \mathrm{C}\right)$. As the result, the linear thermal expansion of FePt is much easier based on the low melting point, which can also be calculated by the formula:

$$
\alpha=\frac{\mathrm{L}_{2}-\mathrm{L}_{1}}{\mathrm{~L}_{0}\left(\mathrm{t}_{2}-\mathrm{t}_{1}\right)}=\frac{\Delta \mathrm{L}}{\mathrm{L}_{0} \Delta \mathrm{t}}
$$

Also, Winkler, et al ${ }^{[20]}$ found that the thermal expansion coefficient was related to the binding energy by referring the equation: $\alpha \propto 1 / \mathrm{E}_{\mathrm{B}}$, where $\mathrm{E}_{\mathrm{B}}$ represents the binding energy of the alloys. The weak bonding energy will induce the large thermal oscillation, which increases thermal expansion.

The formation of $\mathrm{L}_{0}$ - $\mathrm{FePt}$ and the expansion of $\mathrm{MgO}$ matrix mechanisms depending on the deposition temperature from room temperature to $300^{\circ} \mathrm{C}$ are illustrated in Fig. 4. At room temperature deposition, both $\mathrm{FePt}$ and $\mathrm{MgO}$ grains have no sufficient energy for diffusion and expansion. FePt grains are embedded in the $\mathrm{MgO}$ matrix. It suggests that it is difficult to generate the $\mathrm{L} 1_{0}$ phase. As the result, the ordering parameter is relatively low and grain size is small at room temperature deposition. 
After heating the substrate to $200^{\circ} \mathrm{C}$, the size of both $\mathrm{MgO}$ matrix and $\mathrm{FePt}$ grain becomes larger and $\mathrm{L}_{0}$-FePt transformation process is started due to the enough thermal energy supply for the diffusion of $\mathrm{Fe}$ and $\mathrm{Pt}$ atoms. The competitive growth of both of the grains is started, but the $\mathrm{FePt}$ grain expansion and $\mathrm{L}_{0}$-ordering process is dominated due to the large thermal expansion coefficient. Charles, et al ${ }^{[21]}$ also explained that the thermal expansion of $\mathrm{MgO}$ was anisotropic expansion, which extended the in-plane direction axis. Consequently, both the expansion directions of FePt and $\mathrm{MgO}$ are in-plane, which would cause the compression of perpendicular axis. However, when the deposition temperature is further increased to $300^{\circ} \mathrm{C}$, the competitively growth among the grains are more obvious. The size of $\mathrm{MgO}$ grains became large in the films and the FePt grains were surrounded by $\mathrm{MgO}$ matrix. It is known that the $\mathrm{L} 1_{0}$ phase transformation is the process of in-plane axis expansion and perpendicular axis compression. The growth of FePt grains during ordering process is suppressed by the increasing number of growing $\mathrm{MgO}$ grains. Additionally, the atomic diffusivity is increased by elevating the deposition temperature, especially for the $\mathrm{O}$ atoms. As the result, the ordering parameter is decreased and oxidation phase $\left(\mathrm{Fe}_{3} \mathrm{O}_{4}\right)$ is easily appeared, which has been observed by the XRD results.

In order to further illustrate the phase structure affected by $\mathrm{MgO}$ matrix, the $\mathrm{FePt} / \mathrm{MgO}$ bilayer thin film was fabricated to make a comparison with $(\mathrm{FePt})_{45}(\mathrm{MgO})_{55}$ film. Fig. 5a showed the $1_{0}$ - FePt phases were appeared after high temperature annealing in $\mathrm{FePt} / \mathrm{MgO}$ bilayer thin film. The FePt grain size of as-deposited FePt/MgObilayer film was only $15 \mathrm{~nm}$ by calculation. However, the FePt grain size was sharply increased to $40 \mathrm{~nm}$ after $800^{\circ} \mathrm{C}$ annealing. Fig. $5 \mathrm{~b}$ displayed that the FWHM of FePt/MgO bilayer film was much smaller than that of $(\mathrm{FePt})_{45}(\mathrm{MgO})_{55}$ film. It indicated adding $\mathrm{MgO}$ matrix between the FePt grains can minimize the grain size of FePt and form the well-separated granular structure.

\subsection{Magnetic properties}

After $800^{\circ} \mathrm{C}$ annealing, Fig. 6a showed the in-plane coercivity of $(\mathrm{FePt})_{30}(\mathrm{MgO})_{70}$ film deposited at $200^{\circ} \mathrm{C}$ was $3.1 \mathrm{kOe}$. It means the $\mathrm{L} 1_{0}$ phase transformation was started, but the loop showed the obvious two-phase magnetic behavior ${ }^{[22]}$. When the deposition temperature was increased to $300^{\circ} \mathrm{C}$, the film had very low coercivity, shown in Fig. 6b. Since, the FePt decomposed due to the large $\mathrm{MgO}$ fraction (vol. 70\%) and high oxygen atom diffusivity at elevated deposition temperature, which had been explained before. In Fig. 6e, the coercivity showed an upward trend as the 
deposition temperature increased to $200^{\circ} \mathrm{C}$ and then dropped down at $300^{\circ} \mathrm{C}$ deposition. Both the in-plane and out-of-plane coercivity were the highest (6.5kOe and 4.8kOe, respectively) in the $(\mathrm{FePt})_{45}(\mathrm{MgO})_{55}$ film deposited at $200^{\circ} \mathrm{C}$. Moreover, Fig. $6 \mathrm{c}$ showed the appearance of shoulder in the second quadrant, which was originated from the co-existed $\mathrm{L} 1_{0}-\mathrm{FePt}$ and fcc-FePt phases. It was investigated that adding non-magnetic phase would lead to the existence of two phases behavior after heat treatment due to the large exchange length ${ }^{[23]}$. In Fig. 6d, the shape of loop for the film deposited at $300^{\circ} \mathrm{C}$ was similar with that of the film deposited at $200^{\circ} \mathrm{C}$. However, when the fraction of FePt increasing to vol. $60 \%$ in the film, the FePt grains were not well-separated by $\mathrm{MgO}$ matrix and the exchange coupling effects were enhanced, which caused the decrease of coercivity.

Meanwhile, the $\mathrm{M}-\mathrm{H}$ loop of $\mathrm{FePt} / \mathrm{MgO}$ bilayer film deposited at $200^{\circ} \mathrm{C}$ indicated that the in-plane coercivity was slightly decreased $(5 \mathrm{kOe})$ compared with that of $(\mathrm{FePt})_{45}(\mathrm{MgO})_{55} \mathrm{film}$, shown in Fig. 6e. The slope of the hysteresis loop $\left(\alpha_{s}\right)$ at the coercive point is used to reflect the coherency of magnetic reversal process and characterize the exchange coupling effects among FePt grains of in-plane hysteresis loop ${ }^{[12],[16]} . \alpha_{s}$ was obtained by the formula:

$$
\alpha_{\mathrm{s}}=4 \pi\left(\frac{\mathrm{dM}}{\mathrm{dH}}\right)_{\mathrm{H}=\mathrm{H}_{\mathrm{C}}}
$$

The bilayer film showed a behavior like typical rigid magnetic reversal process and the $\alpha$ value was 3 , which represented the enhancement of exchange coupling effect. But the $\alpha$ value was 2.2 for the $(\mathrm{FePt})_{45}(\mathrm{MgO})_{55}$ film deposited at $200^{\circ} \mathrm{C}$, suggesting the exchange coupling among the FePt grains was largely reduced and the domain wall continuous motion was blocked due to adding $\mathrm{MgO}$. As the result, the high coercivity of the $(\mathrm{FePt})_{45}(\mathrm{MgO})_{55}$ film was achieved by the isolated structure.

Fig. 7 displayed the 2D surface morphologies and domain distribution of $200^{\circ} \mathrm{C}$ deposited $(\mathrm{FePt})_{45}(\mathrm{MgO})_{55}$ film and $\mathrm{FePt} / \mathrm{MgO}$ bilayer film annealed at $800^{\circ} \mathrm{C}$. The clear granular structure can be observed by AFM in $(\mathrm{FePt})_{45}(\mathrm{MgO})_{55}$ film, shown in Fig. 7a. Meanwhile, Fig. 7b displayed the smoother surface for $\mathrm{FePt} / \mathrm{MgO}$ bilayer film, despite of some large grains. Additionally, combining analyzing the domain structure, it can be seen that small size domains were uniformly distributed in the $(\mathrm{FePt})_{45}(\mathrm{MgO})_{55}$ film, shown in Fig. 7c. It indicated that the large grains were $\mathrm{MgO}$ matrix in Fig. 7a, with mean size of approximately 100nm. However, Fig. $7 \mathrm{~d}$ displayed that the large size domains was appeared due to the agglomeration of FePt grains, which were exceed the single domain size. These large domains were formed by exchange coupling effects. The strong coupled 
effects between the grains made their moments deviate from the magnetic easy axis, aligning to the same direction. Since, the large size coupled domains may decrease the coercivity. It demonstrated that the domain size and the magnetic properties can be adjusted by adding $\mathrm{MgO}$ non-magnetic matrix.

\section{Conclusion}

We have investigated the effects of adding various fraction of non-magnetic $\mathrm{MgO}$ phase on the phase structure, morphology and magnetic properties of the FePt-MgO granular thin films. It is found that the fraction of $\mathrm{MgO}$ phase has significant effects on the microstructure and magnetic properties of the FePt phase. It is also revealed that the room-temperature co-deposition does not lead to formation of ordered $\mathrm{L} 1_{0}$-FePt hard magnetic phase even after a high temperature annealing. The optimal deposition temperature for the $\mathrm{L} 1_{0}$ phase formation is at $200^{\circ} \mathrm{C}$ with the composition of $(\mathrm{FePt})_{45}(\mathrm{MgO})_{55}$, which is attributed to the well-separated granular structure with reducing exchange coupling effects. Compared with $\mathrm{FePt} / \mathrm{MgO}$ bilayer film, it indicates that the $\mathrm{MgO}$ phase indeed segregates the FePt grains, which gives rise to high coercivity of the FePt-MgO granular film.

\section{Acknowledgement}

This work was supported by Guangdong Provincial Science and Technology Program (Grant No. 2013B090500017, 2013B090500115, 2014B070706023 and 2015A050502015), the Guangzhou Municipal Science and Technology Program (No. 201505041702137) and Zhongshan Municipal Science and Technology Program (Platform construction and innovation team).J. P. Liu thanks support from the US DoD/ARO under grant W911NF-11-1-0507, and the Center for Nanostructured Materials and Characterization Center for Materials and Biology at the University of Texas at Arlington. 


\section{Reference:}

[1] T. Klemmer, D. Hoydick, H. Okumura, B. Zhang, and W. A. Soffa, Scr. Metall. Mater., vol. 33, no.10-11, pp. 1793-1805, 1995.

[2] C. P. Luo and D. J. Sellmyer, Appl. Phys. Lett., vol. 75, pp. 3162-3164, 1999.

[3] M. Watanabe, T. Masumoto, D. H. Ping, and K. Hono, Appl. Phys. Lett., vol. 76, pp. 3971-3973, 2000.

[4] H. S. Ko, A. Perumal, and S. C. Shin, Appl. Phys. Lett., vol. 82, pp. 2311-2313, 2003.

[5] Y. Zhang, J. Wan, V. Skumryev, S. Stoyanov, Y. Huang, G. C. Hadjipanayis, and D. Weller, Appl. Phys. Lett., vol. 85, pp. 5343-5345, 2004.

[6] G. Yang, D. L. Li, S. G. Wang, Q. L. Ma, S. H. Liang, H. X. Wei, X. F. Han, et al, J. Appl. Phys., 117, 083904,2015.

[7] A.Kohn, N.Tal, A.Elkayam, A.Kovacs, D. L. Li, S. G. Wang, et al,Appl Phys Lett., 102(6), 062403 - 062403-5, 2013.

[8] K. Kang, Z. G. Zhang, C. Papusoi, and T. Suzuki, Appl. Phys. Lett., vol. 84, pp. 404-406, 2004.

[9] M. Tanaka, Y. Ogata, and S. Nakagawa, J. Appl. Phys., vol. 109, 07B716, 2011.

[10] Y. Peng, J. G. Zhu, and D. E. Laughlin, J. Appl. Phys., vol. 99, pp. 08F907-1-0F907-3, 2006.

[11] X. Y. Zhan, Y Zhang,Y. S.Gu,andJ. M. Li, Rare Met.,Vol.25, Spec. Issue, p.58, 2006.

[12] J. H. Yin, A. K. Singh, T. Suzuki, Fellow, IEEE, and Z. G. Zhang, IEEE. Trans. Magn., vol. 41, no. 10, pp. 3208-3210, 2005.

[13] Z.Dong, et al, Rare Met.,25(6), 436-439, 2006.

[14] J. Liu, Y. P. Zeng, H. Y. Yu, D. L. Jiao, Z. G. Zheng, Z. W. Liu, and G. Q. Zhang, Appl. Surf. Sci., vol. 300, pp. 124-128, 2014.

[15] N. Xiao, B. Yang, J. S. Wang,S. Li, Y. P. Ren, and G. W. Qin, Rare Met., 35(6), 463-470, 2016.

[16] A. C. Sun, Y. C. Tsai , Fu-Te Yuan, Jen-Hwa Hsu, and P. C. Kuo, IEEE. Trans. Magn., vol. 44, no. 11, pp. 3531-3534, 2008.

[17] T. J. Zhou, M. H. Lu, L. Shen, R. Q. Wee, et al, IEEE. Trans. Magn., vol. 50, no. 1, 2300105, 2014. 
[18] C.B. Rong, D. Li, V. Nandwana, N. Poudyal, Y. Ding, Z.L. Wang, H. Zeng, and J.P. Liu, Adv. Mater., vol. 18, pp. 2984-2988, 2006.

[19] T. Carnelly, Ber. Deut. Chem. Ges., vol. 12, pp. 439, 1879

[20] H. G Winkler, Crystal structure and crystal properties, Science Press, Bei Jing, 1960

[21] J. Charles, Engberg, and E. H. Zehms, J. Am. Ceram. Soc., vol. 42, pp. 300-305, 2006

[22] L. W. Liu, Q. Li, H. G. Dang, L. Hao, J. W. Cao, Y. B. Li, Y. Wang, J. M. Bai, and F. L. Wei, Appl. Surf. Sci., vol. 273, pp. 243-246, 2013.

[23] J. Liu, Z.W. Liu, H.Y. Yu, D.L. Jiao, D.C. Zeng, S.L. Hu, and G.Q. Zhang, J. Magn. Magn. Mater., vol. 336, pp. 55-60, 2013. 
Figure Captions:

Fig. $1 \mathrm{XRD}$ patterns and the ordering parameter for $\mathrm{FePt}-\mathrm{MgO}$ films annealed at $800^{\circ} \mathrm{C}$, (a) $(\mathrm{FePt})_{30}(\mathrm{MgO})_{70} ;(\mathrm{b})(\mathrm{FePt})_{45}(\mathrm{MgO})_{55} ;(\mathrm{c})(\mathrm{FePt})_{60}(\mathrm{MgO})_{40}$; (d) ordering parameter depended on deposition temperature

Fig. 2 Magnified XRD patterns and the grain size variation of FePt-MgO films annealed at $800^{\circ} \mathrm{C}$, (a) $(\mathrm{FePt})_{45}(\mathrm{MgO})_{55} ;$ (b) $(\mathrm{FePt})_{60}(\mathrm{MgO})_{40} ;$ (c) Average FePt grain size depended on deposition temperature

Fig. 3 Plane-view TEM images and SAEDs for $(\mathrm{FePt})_{45}(\mathrm{MgO})_{55}$ film, (a) deposited at $200^{\circ} \mathrm{C}$; (b) deposited at $300^{\circ} \mathrm{C}$

Fig. 4 Schematic of the competitively growth of FePt and $\mathrm{MgO}$ grains depended on deposition temperature

Fig. 5 (a) XRD patterns for FePt/MgO bilayer films deposited at $200^{\circ} \mathrm{C}$ and annealed at $800^{\circ} \mathrm{C}$; (b) Magnified XRD patterns for $200^{\circ} \mathrm{C}$ deposited $\mathrm{FePt} / \mathrm{MgO}$ bilayer films and $(\mathrm{FePt})_{45}(\mathrm{MgO})_{55}$ film annealed at $800^{\circ} \mathrm{C}$

Fig. 6 Hysteresis loops and in-plane coercivity variations of FePt-MgO granular films and FePt/MgO bilayer film annealed at $800^{\circ} \mathrm{C}$, (a) $(\mathrm{FePt})_{30}(\mathrm{MgO})_{70}$ film deposited at $200^{\circ} \mathrm{C}$; (b) $(\mathrm{FePt})_{30}(\mathrm{MgO})_{70}$ film deposited at $300^{\circ} \mathrm{C}$; (c) $(\mathrm{FePt})_{45}(\mathrm{MgO})_{55}$ film deposited at $200^{\circ} \mathrm{C}$; (d) $(\mathrm{FePt})_{60}(\mathrm{MgO})_{40}$ film deposited at $200^{\circ} \mathrm{C}$ (e) $\mathrm{FePt} / \mathrm{MgO}$ bilayer film deposited at $200^{\circ} \mathrm{C}$; (f) in-plane coercivity variations corresponding to deposition temperature of FePt-MgO granular films

Fig. 7 AFM and MFM images of FePt-MgO granular film and FePt/MgO bilayer film annealed at $800^{\circ} \mathrm{C}$, (a) AFM image of $(\mathrm{FePt})_{45}(\mathrm{MgO})_{55}$ film deposited at $200^{\circ} \mathrm{C}$; (b) $\mathrm{AFM}$ image of $\mathrm{FePt} / \mathrm{MgO}$ bilayer film deposited at $200^{\circ} \mathrm{C}$; (c) MFM image of $(\mathrm{FePt})_{45}(\mathrm{MgO})_{55}$ film deposited at $200^{\circ} \mathrm{C}$; (d) MFM image of $\mathrm{FePt} / \mathrm{MgO}$ bilayer film deposited at $200^{\circ} \mathrm{C}$ 

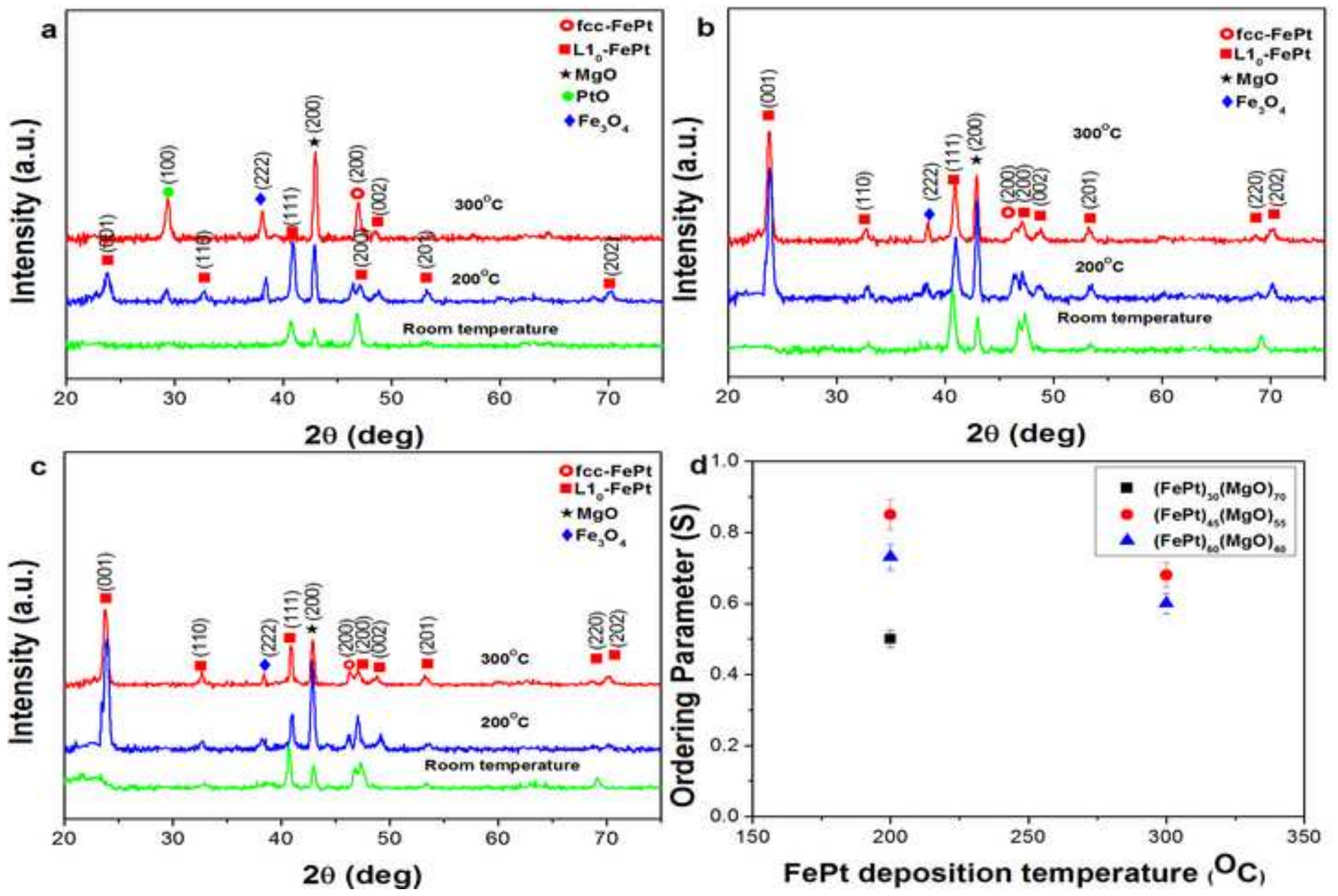

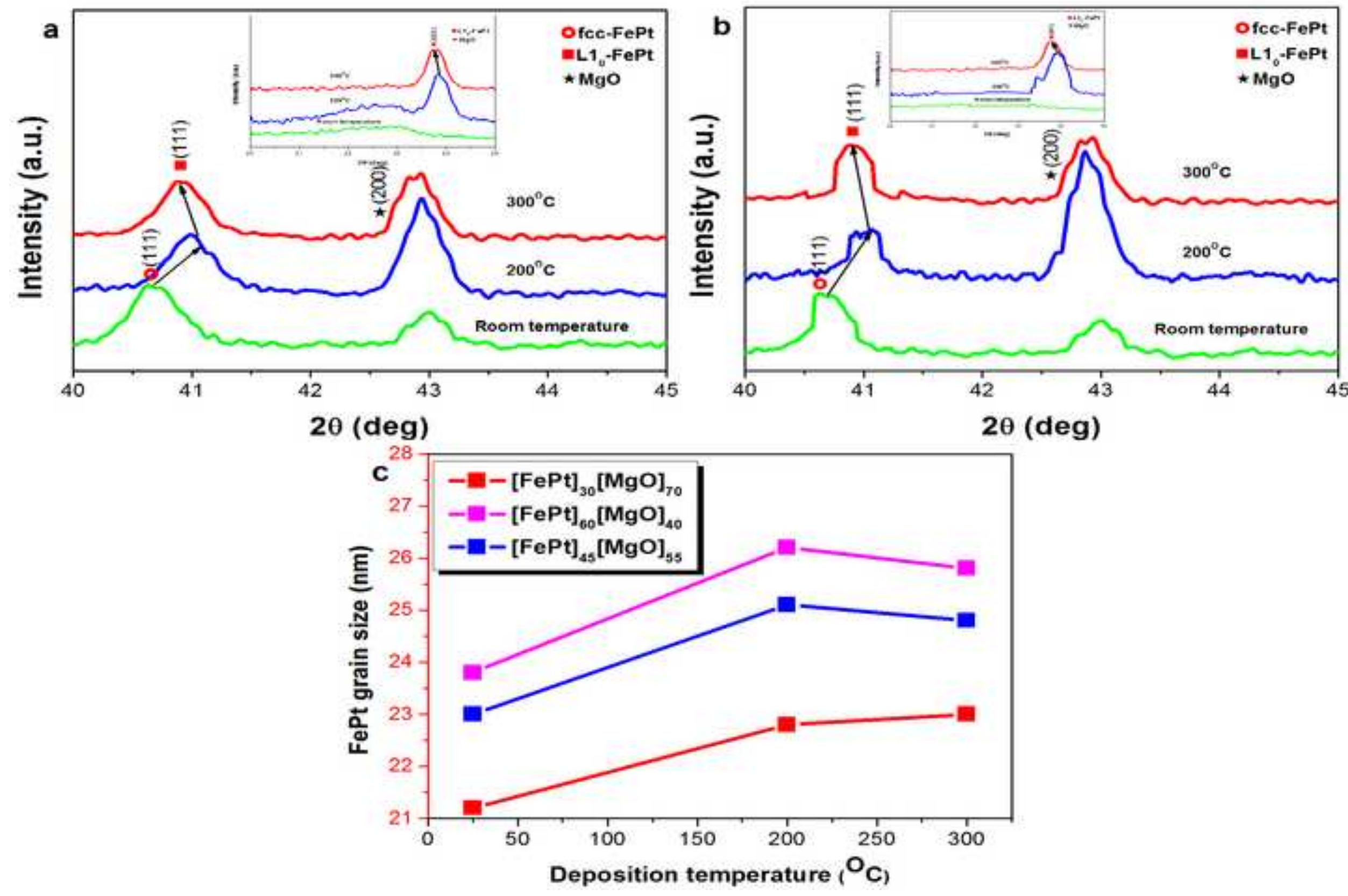

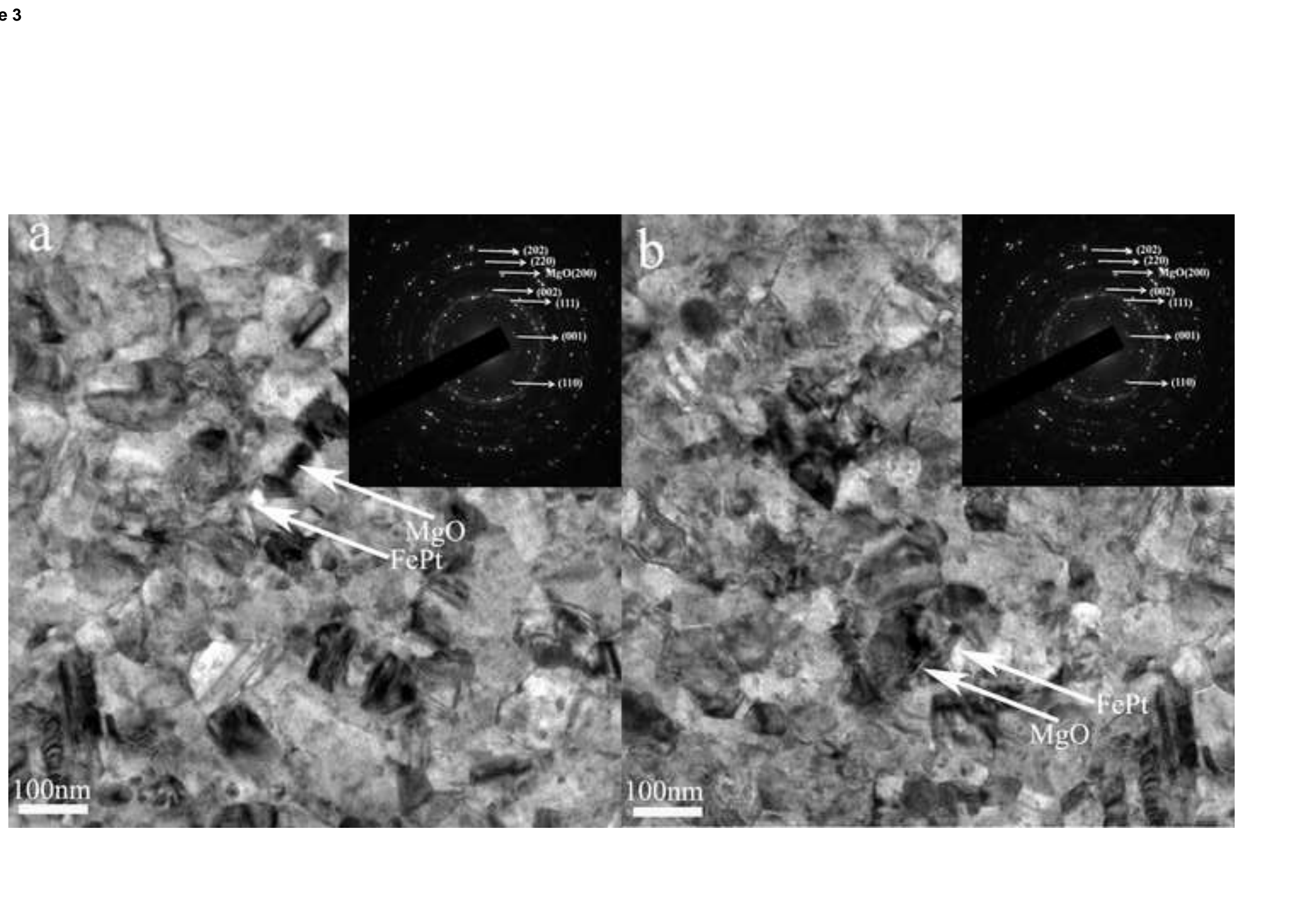


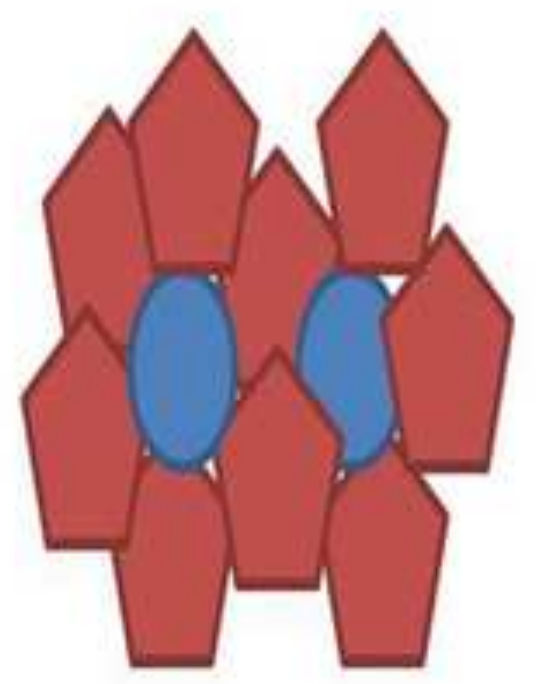

Room temperature
deposition

Room temperature
deposition

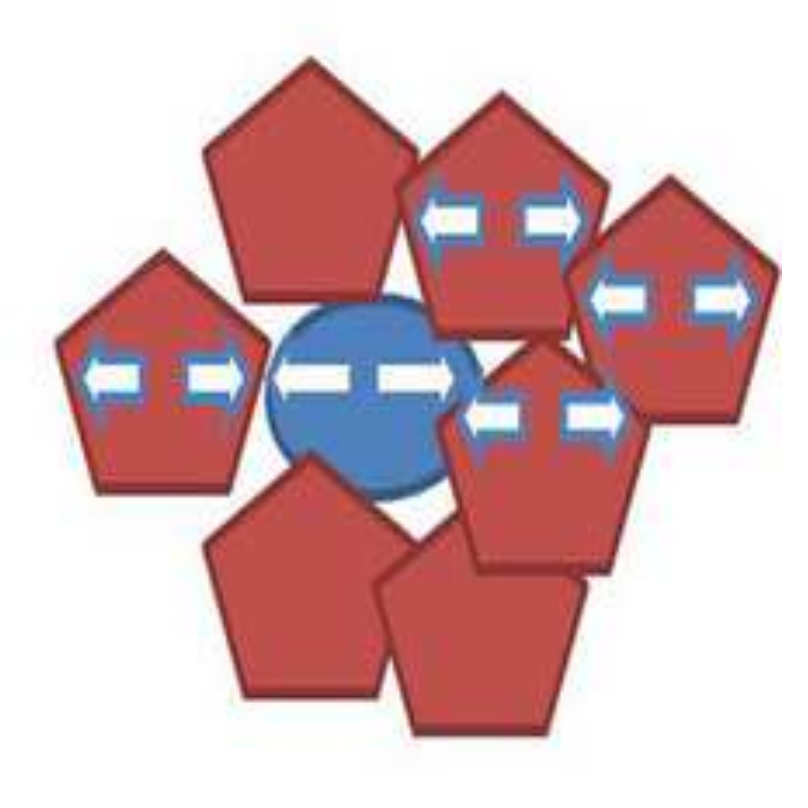

$300^{\circ} \mathrm{C}$ deposition

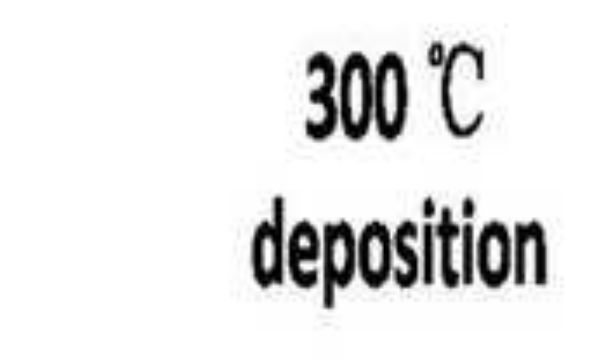

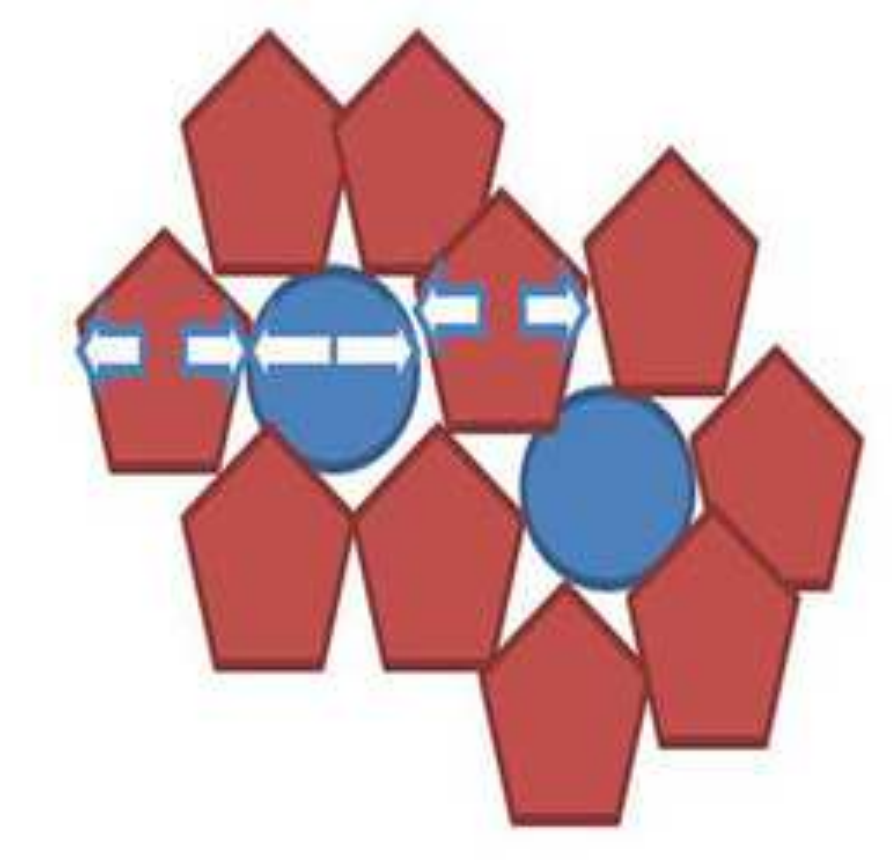

$200^{\circ} \mathrm{C}$ deposition depostion

\section{Fept \\ $\mathrm{MgO}$

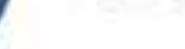

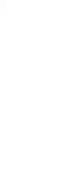

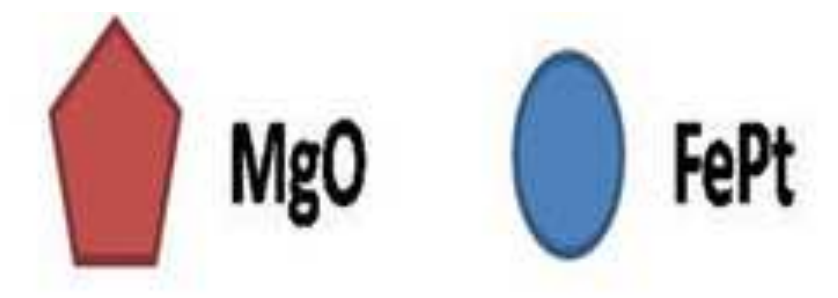



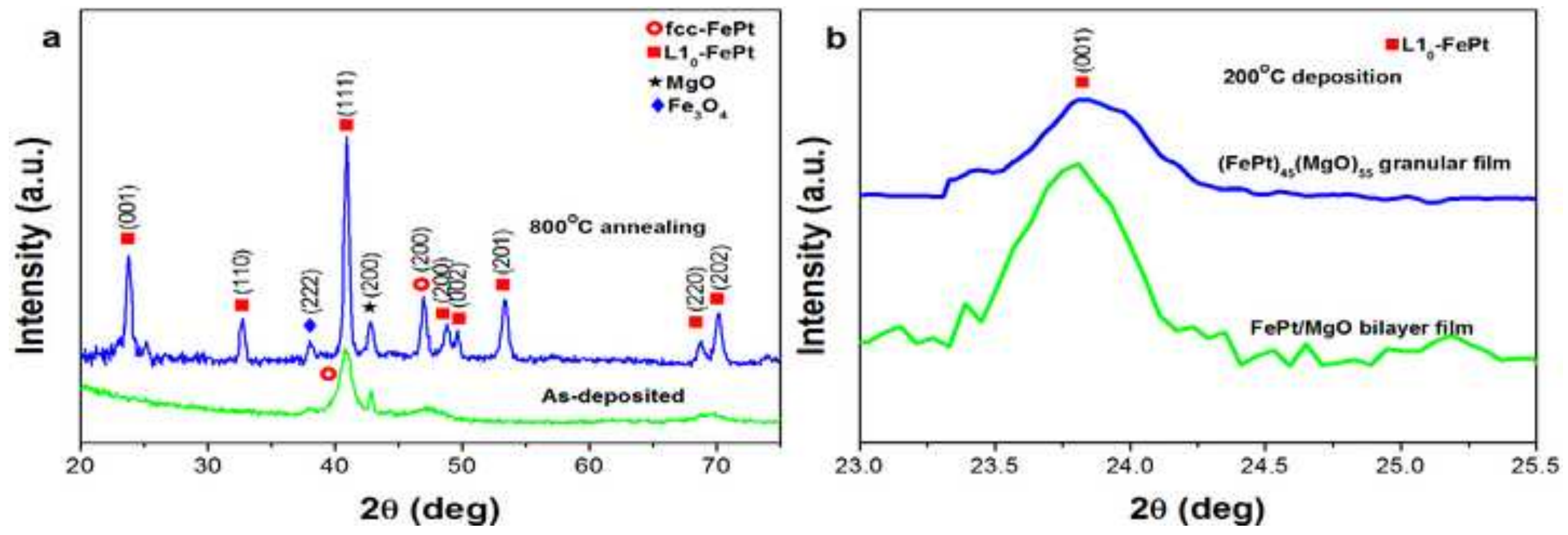

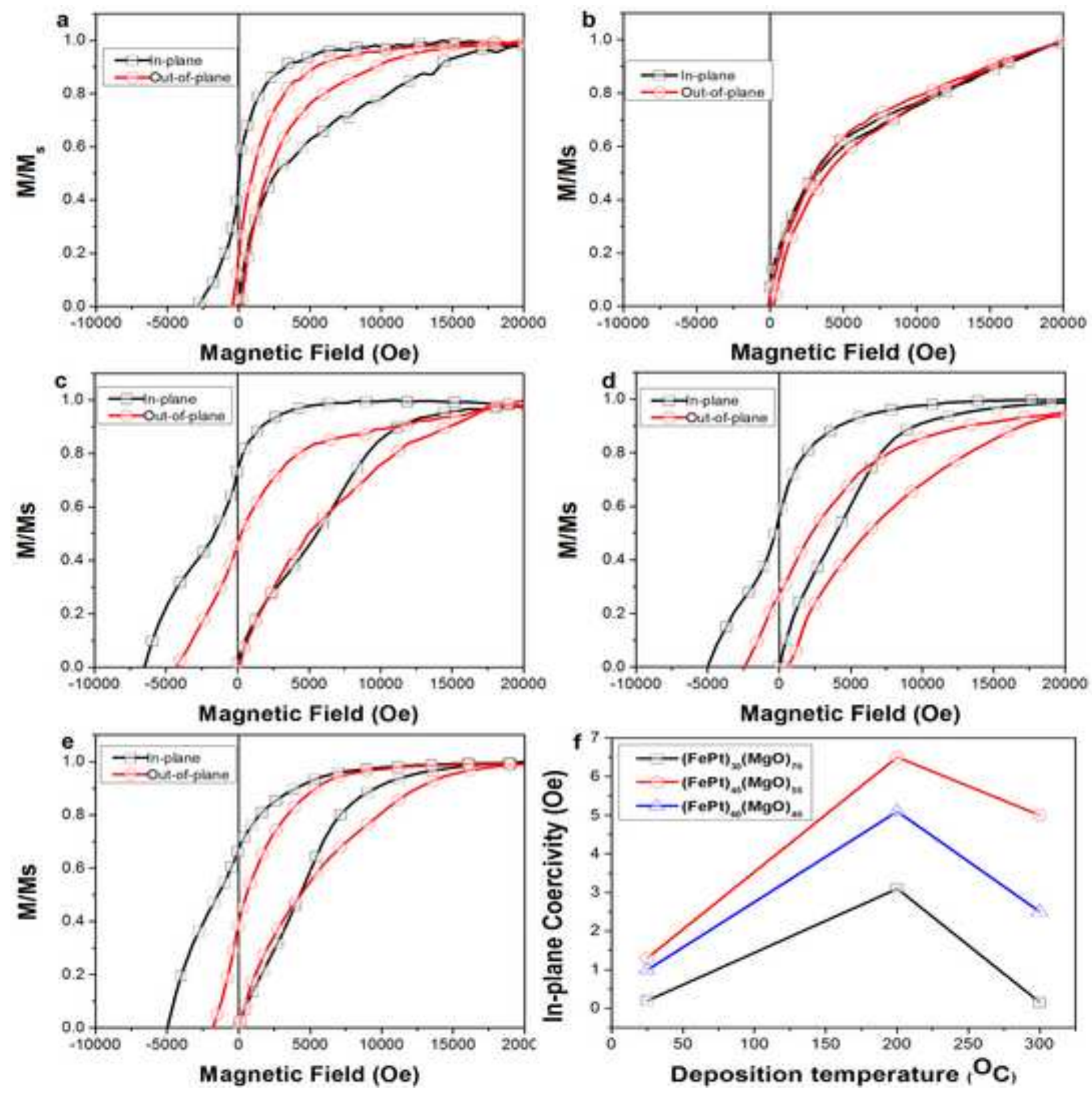


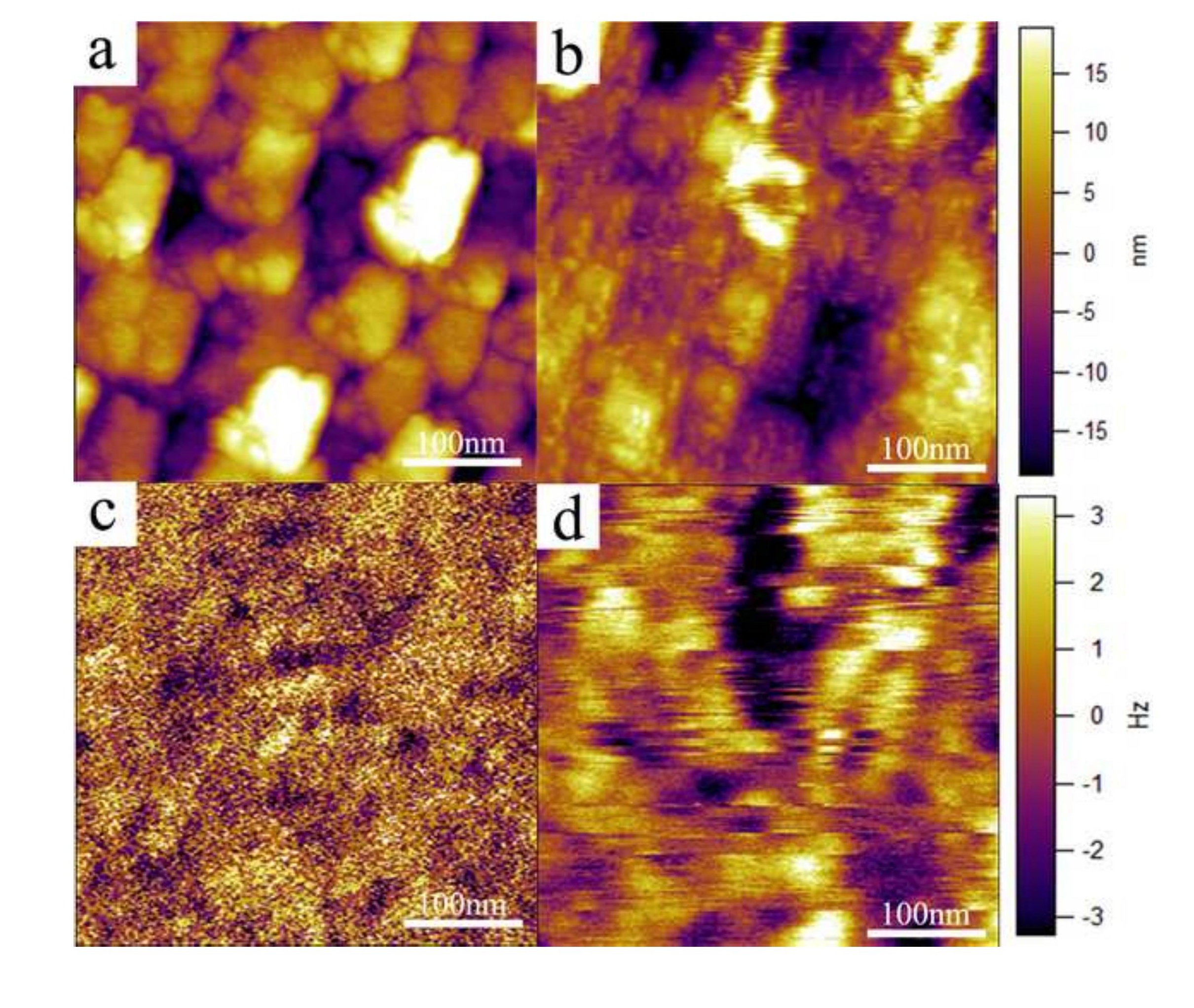

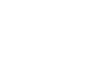

\section{Figure 7}

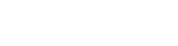

.
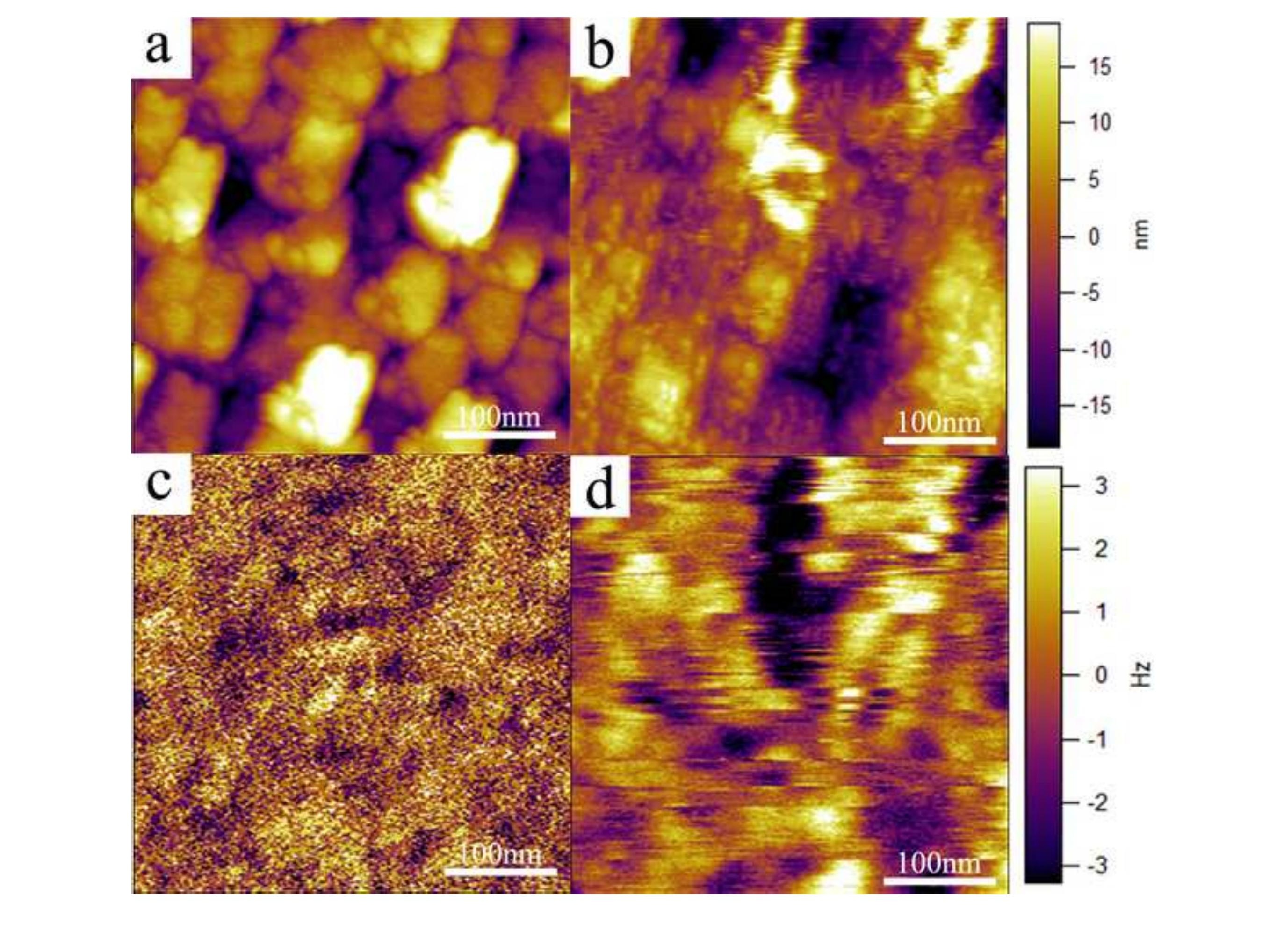